\title{
Treatment and quality of life for people with ALS
}

Jeffrey Fletcher, MD

\section{What is ALS?}

Amyotrophic lateral sclerosis (ALS) is also known as motor neuron disease and Lou Gehrig disease. It is a degenerative disease of the neurons (nerve cells) in the brain and spinal cord that causes progressive weakness of the arms and legs, eventually leading to total paralysis. At this time there are treatments available that can help with some of the symptoms of ALS, but there is no cure. More information about ALS and some of the available treatments can be found on the next page.

\section{Minocycline as a new treatment for ALS}

In this issue of Neurology, Gordon et al. ${ }^{1}$ report on two small studies of a drug called minocycline in patients with ALS. Minocycline is approved to manage infection. It has also been effective in slowing down brain damage in animal models of diseases like stroke and Parkinson disease. We think it does this by protecting the brain against the bad effects of inflammation. Investigators compared two doses of minocycline with placebo (dummy or sugar pill) to see whether the drug would be safe in patients with ALS. There were not enough patients enrolled at either dose to test whether the drug was effective at slowing down the disease. The investigators found that patients with ALS who took the lower dose of minocycline had no more side effects than people taking the placebo. More side effects were seen in the patients taking the higher dose. These included gastrointestinal problems and liver and kidney abnormalities. Based on the findings that patients with ALS can safely take minocycline, the investigators have begun a larger study that will test whether minocycline can slow down the symptoms of ALS. Until the results of this ongoing study are known, we do not recommend using minocycline in patients with ALS. The reason for this is that minocycline may not actually work to slow down symptoms and may cause side effects in some patients.

\section{Relationship between ALS patients and their caregivers}

Another problem facing patients with ALS and their families is that at the end stage of ALS, patients become completely dependent on someone else to care for them. Also in this issue of Neurology, Adelman et al. ${ }^{2}$ study the relationship between the end-stage ALS patient and their caregiver. The purpose was to determine the agreement between the primary caregiver and the ALS patient about the patient's physical and psychological status. The study also looked at how much of a burden the care of the sick patient was on the caregiver and the patient's views about how large a burden the caregiver had. The study compared different pairs of patients and their caregivers repeatedly over time. The study found that caregivers accurately reported information about a patient's physical function and degree of pain at the end of life. However, the study also found that caregivers were not in agreement with patients about some of the psychological impacts of the disease. Caregivers commonly assumed a greater degree of suffering than the patient really felt. The patients also seemed to assume that their care was more burdensome for the caregiver than it really was.

\section{Why are these studies important?}

Because there is no cure for ALS, more medical research is needed to keep looking for effective treatments. If you have ALS or are a caregiver for a patient with ALS you should ask your doctor whether there are any research studies available for you to participate in.

The relationship between ALS patients and their caregivers is extremely important. Many ALS patients lose the ability to communicate effectively about their health problems during the latter part of their illness. The caregiver then becomes the primary person giving information to the physician about the patient's health. The caregiver also helps patients with activities they can no longer perform for themselves, such as getting out of bed or feeding themselves. If the caregiver is not accurate with providing information about the patient's current health status, problems such as depression, pain, or breathing difficulties may go unnoticed. Also, patients who feel their caregiver is overly burdened may not discuss problems or ask for help when they need it. Conversely, if the patient is not aware of the difficulties the caregiver is having, this could lead to problems as well. Accurate and honest communication between the caregiver and patient is essential to ensure the patient receives good medical care and to manage some of the psychological issues surrounding ALS. 


\section{What is ALS?}

ALS is also known as motor neuron disease and Lou Gehrig disease. It is a degenerative disease of the neurons (nerve cells) in the brain and spinal cord that causes progressive weakness of the arms and legs, eventually leading to total paralysis. The disease also affects nerves involved in breathing, speaking, and swallowing; therefore, patients will eventually become unable to eat or breathe on their own. Despite the devastating problems with paralysis, most patients will not have problems with their thinking and memory. However, communication does become a problem because patients eventually will not be able to speak or write. For $80 \%$ of people, weakness tends to progress, causing death in 3 to 5 years. Some of the signs and symptoms of ALS are shown in the bulleted list below.

ALS can strike anyone and at any age, but it generally occurs between the ages of 40 and 70 years. An estimated 5,000 people in the United States are diagnosed with ALS each year.

\section{What are the symptoms?}

ALS usually comes on slowly. The first signs are often arm or leg weakness, problems with speaking or swallowing, muscle twitches or cramps or loss of muscle tissue, tight or stiff muscles, and fatigue. Some people laugh or cry more easily. In time, all muscles involved with voluntary movement are affected. ALS does not affect involuntary muscles, such as those that control the heart and the digestive system.

\section{How is ALS diagnosed?}

There is no specific test to diagnose ALS. Several tests, including nerve conduction studies and electromyogram (EMG), measure how well the nerves are working. Excluding other causes of muscle weakness is important.

\section{What causes ALS?}

The cause of ALS is not known. Five to $10 \%$ of those with ALS have a family history of the disorder and show a genetic pattern. In this form, offspring have approximately a $50 \%$ chance of developing ALS. This is called familial ALS.

\section{What are the treatments?}

There is no known cure for ALS, but research is promising. The drug riluzole modestly increases survival time. Other potential treatments are under investigation.

The primary treatment is managing ALS symptoms. People with ALS need to take an active role in planning and carrying out their treatment. Ideally, physical, occupational, speech, respiratory, and nutrition therapy will be involved. A neurologist is the doctor best qualified to work with the treatment team.

Learning you have ALS can lead to feelings of anxiety, fear, and depression. It is not unusual to feel overwhelmed or numb. Your family and friends may share these feelings. Your doctor, therapists, and support groups can help you and your family and friends through the difficult times ahead. It is important to talk about the diagnosis and what it means to you.

Common symptoms of ALS include:

- Weakness in the hands and feet

- Trouble walking

- Trouble breathing or lying flat

- Changes in voice

- Trouble swallowing

- Pain in joints

- Depression

- Fatigue

- Cramps

- Insomnia

- Anxiety

- Constipation

\section{For more information}

American Academy of Neurology

Foundation

www.thebrainmatters.org

ALS Association

www.alsa.org

International Alliance of ALS/MND

Associations

www.alsmndalliance.org

\section{References}

1. Gordon PH, Moore DH, Gelinas DF, et al. Placebo-controlled phase I/II studies of minocycline in amyotrophic lateral sclerosis. Neurology 2004;62:1845-1847.

2. Adelman EE, Albert SM, Rabkin JG, Del Bene ML, Tider T, O'Sullivan I. Disparities in perceptions of distress and burden in ALS patients and family caregivers. Neurology 2004;62:1766-1770. 


\title{
Neurology
}

\author{
Treatment and quality of life for people with ALS \\ Jeffrey Fletcher \\ Neurology 2004;62;E22-E23 \\ DOI 10.1212/WNL.62.10.E22
}

This information is current as of May 24, 2004

\section{Updated Information \&} Services

References

Citations

Permissions \& Licensing

Reprints including high resolution figures, can be found at: http://n.neurology.org/content/62/10/E22.full

This article cites 2 articles, 2 of which you can access for free at: http://n.neurology.org/content/62/10/E22.full\#ref-list-1

This article has been cited by 1 HighWire-hosted articles: http://n.neurology.org/content/62/10/E22.full\#\#otherarticles

Information about reproducing this article in parts (figures,tables) or in its entirety can be found online at:

http://www.neurology.org/about/about_the_journal\#permissions

Information about ordering reprints can be found online:

http://n.neurology.org/subscribers/advertise

Neurology ${ }^{\circledR}$ is the official journal of the American Academy of Neurology. Published continuously since 1951, it is now a weekly with 48 issues per year. Copyright . All rights reserved. Print ISSN: 0028-3878. Online ISSN: 1526-632X.

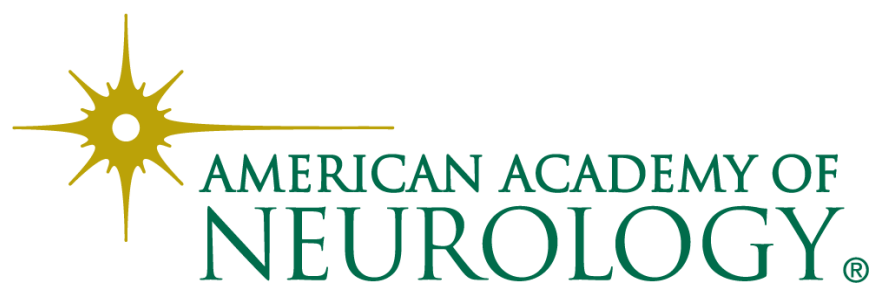

